\title{
Outcome of the elderly patient in intensive care: a cohort study
}

\author{
AD Impiumi \\ From ESICM LIVES 2015 \\ Berlin, Germany. 3-7 October 2015
}

\section{Introduction}

The world population is ageing, by 2050 the percentage of the population older than 80 years will double. Older age is associated with higher prevalence of chronic illness and functional impairment, contributing to an increased rate of hospitalization and admission to Intensive Care Units.

\section{Objectives}

To assess if age is an important and independent predictor of the mortality rate of patients of 80 years old and older who are admitted to the Intensive Care Unit.

\section{Methods}

Retrospective cohort study. We included all patients admitted to the polivalent Intensive Care Units ISTAR 1 and ISTAR 2 in 2011 and 2013 until June. Patients were categorized into three age groups: less than 80 years old, 80-85 years old and above 85 years old. Age, type of admission, comorbidities, hospital outcome and duration of recovery were analyzed. Bivariate and multivariate analysis were used to analyze age, type of admission (surgery versus medical versus emergency) and comorbidities' influence on hospital outcome. Kruskal-Wallis test was used to compare duration of recovery in our three age groups. Kaplan-Meier survival curves of the three age groups were designed and compared with the log-rank test.

\section{Results}

Age, as a standalone factor, is a significant predictor of mortality rate among patients admitted to the Intensive Care Unit $(\mathrm{p}=0.0290)$. The type of admission is even more strongly associated with mortality $(\mathrm{p}<0.0001)$. $\operatorname{BPCO}(\mathrm{p}=0.0446)$ and cardiopathy $(\mathrm{p}=0.0028)$ are significant predictor factors of hospital outcome, while cancer is not ( $\mathrm{p}=0.5676)$.

\section{Conclusions}

Age resulted to be a significant predictor of mortality rate, but not as much as COPD and cardiopathy, that seem to be better predictors. Age does not appear to be the only criteria upon which evaluate the aptness to admit a patient to the Intensive Care Unit.

\section{Grant Acknowledgment}

From this study we have learnt that age must be taken into account when deciding whether or not to admit a patient in Intensive Care but with all the other variables such as comorbidities and type of admission, which are shown to be even more significant than age itself to predict the outcome of the patient.

Published: 1 October 2015

\section{References}

1. Nguyen $Y L$, Angus DC, Boumendil A, Guidet B: The challenge of admitting the very elderly to intensive care. Ann Intensive Care 2011, 1(1):29.

2. Boumendil A, Guidet B: Elderly patients and intensive care medicine. Intensive Care Med 2006, 32(7):965-967.

3. Garrouste-Orgeas M, Timsit JF, Montuclard L, Colvez A, Gattolliat O, Philippart F, et al: Decision-making process, outcome, and 1-year quality of life of octogenarians referred for intensive care unit admission. Intensive Care Med 2006, 32(7):1045-1051.

4. de Rooij Se, Abu-Hanna A, Levi M, de Jonge E: Factors that predict outcome of intensive care treatment in very elderly patients: a review. Crit Care 2005, 9(4):R307-R314.

5. Somme D, Maillet JM, Gisselbrecht M, Novara A, Ract C, Fagon JY: Critically ill old and the oldest-old patients in intensive care: short- and long-term outcomes. Intensive Care Med 2003, 29(12):2137-2143.

doi:10.1186/2197-425X-3-S1-A531

Cite this article as: Impiumi: Outcome of the elderly patient in intensive care: a cohort study. Intensive Care Medicine Experimental 2015 3(Suppl 1): A531. 